\title{
Integrasi Web Services Dengan Menggabungkan Perancangan Berorientasi Objek dan SOA Untuk Membangun Sistem e-Learning
}

\author{
Supriyono \\ Jurusan Teknik Informatika, Sains dan Teknologi \\ Universitas Islam Negeri (UIN) Maulana Malik Ibrahim Malang \\ supriyono.uin@gmail.com
}

\begin{abstract}
Abstrak-Web services sangat mendukung dalam penggunaan aplikasi yang terintegrasi. Dengan adanya sistem web services tersebut diharapkan dapat meningkatkan kolaborasi antar pemrogram dan antar organisasi bisnis, yang memungkinkan suatu fungsi dalam web services dapat digunakan oleh aplikasi lain tanpa perlu mengetahui detil pemrograman yang terdapat di dalamnya. Web Services cocok untuk menyelesaikan masalah pada sistem bisnis konsep lama ke sistem bisnis terintegrasi, sehingga dengan satu model konsep bisnis dapat diakses dan dipergunakan oleh bermacam-macam aplikasi yang diperlukan. Pada penelitian berikut akan mengintegrasikan web services untuk membangun sistem e-learning. Permasalahan utama didalam sistem e-Learning adalah kesulitan dalam sharing resource dan pencarian data. Sebagian besar masalah tersebut disebabkan karena lemahnya mekanisme sharing dan sumber learning pada web semantic. Dengan melakukan integrasi web services dengan cara menggabungkan Perancangan Berorientasi Objek dan Software Oriented Architectures dapat digunakan untuk membangun sebuah sistem e-Learning dan mengatasi permasalahan pada sharing resource dan pencarian data. Sumber learning didefinisikan dalam bentuk ontologi dan pertukaran informasi didukung dengan layanan web services.
\end{abstract}

Kata Kunci : web services, learning, sharing, resource, Software Oriented Architectures

\section{PENDAHULUAN}

Web services merupakan aplikasi yang sangat modular, karena mampu berdiri sendiri serta menggambarkan dan menjelaskan dirinya sendiri, dan dapat dipanggil melalui internet maupun intranet. Web service sendiri pada prinsipnya berisikan logika aplikasi dan juga data. Web Services Sepenuhnya berdasarkan standard web dan $\mathrm{xml}$.

Web services menjadi populer saat ini karena mampu mengintegrasikan aplikasi yang berbeda platform secara lebih sederhana dan mampu memperbaiki kelemahan dari middleware konvensional seperti RPC, CORBA, dan Java RMI.

Kelemahan utama dari middleware konvensional adalah tidak mendukung heterogenitas, membutuhkan protokol sendiri (tidak pervasive), membutuhkan effort yang besar pada perubahan aplikasi, dan sulit untuk digunakan kembali (tidak reusable)[4]. Web services dibangun berdasarkan teknologi yang terbuka seperti[2]:

1. eXtensible Markup Language (XML)

2. Simple Object Access Protocol (SOAP)

3. Universal Description, Discovery and Integration (UDDI)

4. Web Servicess Description Language (WSDL)
Kegunaan dari web services diantaranya dapat dilakukannya integrasi antar-aplikasi yang tersebar, pengaksesan service oleh berbagai jenis bahasa pemrograman yang telah dilakukan[1]. Pada saat ini XML Web services semakin banyak digunakan oleh kalangan enterprise untuk memudahkan akses pada produknya, meningkatkan layanan ke konsumen, dan ke bussiness partner melalui internet atau corporat extranet[5]. Banyak kelebihan yang ditawarkan oleh web service terutama dari tingkat interoperabilitas tinggi dan penggunaannya yang dapat diakses kapanpun dan dimanapun selama masih terhubung oleh jaringan internet. Gambar 1 berikut mendeskripsikan gambaran umum dari web service.

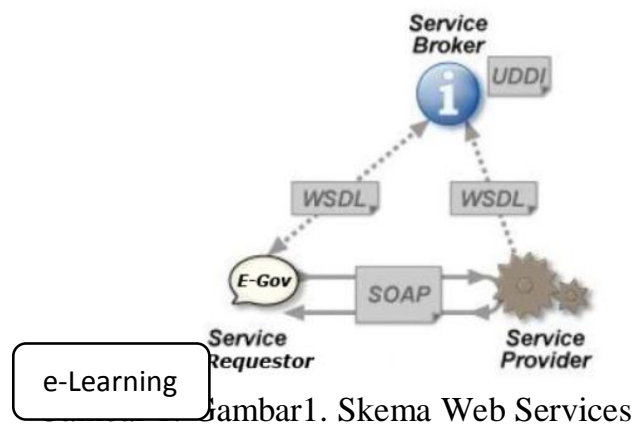

Penggunaan objek dalam lingkungan serviceoriented masih sedikit yang mendukung dan belum 
sepenuhnya dieksplorasi [2]. Namun, teknologi web services sudah cukup kuat untuk melayani sebagai komunikasi middleware dalam SOA serta berbasis aplikasi DOA. Integrasi BPEL ke dalam objectoriented telah diusulkan sebelumnya[9].

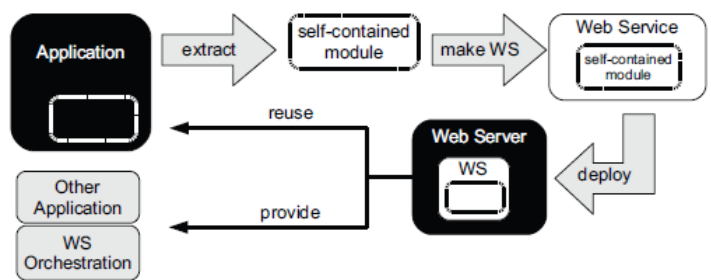

Gambar 2. Mengekspos Legacy Class sebagai web services

Teknologi SOAP (simple object access protocol), WSDL (web service description language) dan UDDI (universal description, discovery and integration) digunakan untuk mendeskripsikan, mempublish dan mengakses berbagai macam objek.

Meratanya e-learning dikalangan masyarakat menyebabkan instansi pemerintah, sekolah dan perusahaan swasta membangun website e-learning. Bagaimanapun juga e-learning yang ada dibangun dari berbagai macam bahasa pemrograman, format penyimpanan data, dan sistem arsitektur yang bermacam-macam sehingga menyebabkan beberapa masalah yang berkaitan dengan interoperabilitas[8]. Oleh karena itu, dalam penelitian ini mengintegrasikan web services dengan menggabungkan perancangan berorientasi objek dan Software Oriented Architectures agar dapat menyelesaikan berbagai macam permasalahan didalam membangun e-learning secara efektif dan efisien.

Struktur makalah ini te rdiri atas 6 bagian. Bagian pertama berisi pendahuluan. Bagian ke dua berisi dasar teori e-Learning. Bagian ketiga berisi penjelasan mengenai web servies. Bagian keempat berisi penjelasan intelligent agent dan SOA. Bagian kelima berisi kerangka kerja sistem. Bagian keenam berisi simpulan dan saran.

\section{E-Learning}

E-learning adalah suatu pemanfaatan teknologi jaringan yang bertujuan menyampaikan pengetahuan pada saat kapan saja dan dimana saja. Setiap jenis pembelajaran yang menggunakan bahan ajar tidak dalam bentuk kertas konvensional dan membutuhkan penggunaan peralatan elektronik secara luas disebut sebagai e-learning[8]. Elearning atau dikenal sebagai pembelajaran secara on-line dan jarak jauh, mengacu pada pengajaran secara interaktif dan belajar mandiri yang tidak terbatas pada waktu dan ruang serta melalui internet, teknologi informasi atau media peralatan yang lainnya.

Oleh karena itu, aplikasi e-learning perlu dikembangkan secara maksimal untuk dapat menyediakan layanan pembelajaran elektronik. Organisasi pendidikan dapat menyediakan informasi yang diperlukan dengan cepat, fleksibel dan efektif untuk peningkatan dan perbaikan kinerja pembelajaran secara on-line [7]. Dalam penelitian sebelumnya, teknik rekayasa perangkat lunak dengan cara menggabungkan paradigma Generic Programming dan Service-Oriented Architectures ke dalam bentuk web services sehingga dihasilkan sebuah generic, reusable dan extensible platform yang disebut dengan Collaborative Learning Purpose Library untuk pengembangan secara sistematik dari aplikasi pembelajaran sesuai dengan kebutuhan yang diperlukan [10]. Gambar 3 mendeskripsikan gambaran umum e-learning.

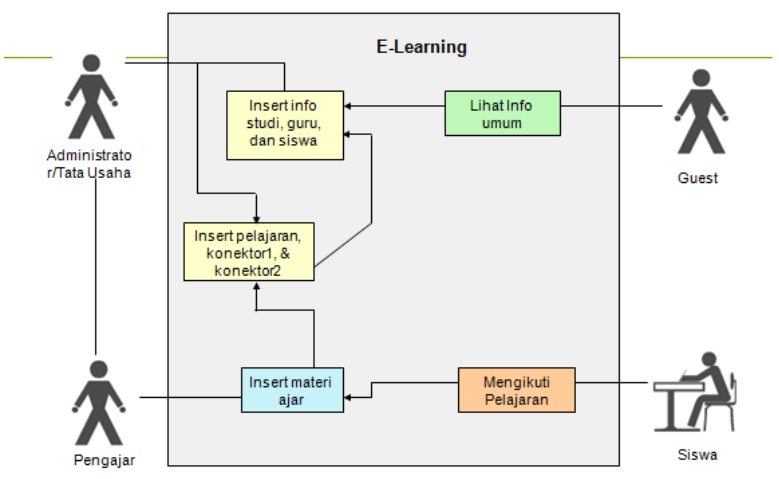

Gambar 3. Gambaran Umum e-Learning

\section{Web Services}

Web service terbentuk melalui beberapa komponen pendukung, diantaranya adalah SOAP, WSDL, UDDI, serta dokumen XML. Bagianbagian komponen tersebut memiliki tugas tersendiri yang saling mendukung diantara satu dengan lainnya. 


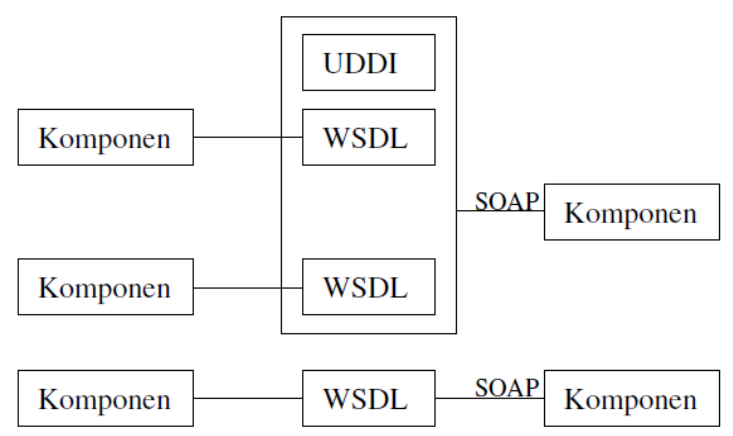

Gambar 4. Komponen Pendukung Web Services

Implementasi SOAP dalam web service dilakukan ketika membuat dokumen XML atau String yang kemudian mengirimkan fasilitas data dan memanggil metode di antara aplikasi. SOAP memungkinkan fungsi public atau metode untuk melakukan query melalui antar muka XML. Begitu aplikasi melakukan query fungsi public atau metode aplikasi lain, sekaligus akan mengirimkan data fungsi atau metode tersebut dan mendapatkan hasil kembali. Sebenarnya fungsi public atau metode tidak harus selalu digunakan, namun merupakan penerapan yang tepat ketika melakukan pengembalian data.

SOAP sangat membantu dalam pertukaran data diantara fungsi atau metode, namun tidak dapat membantu untuk menjelaskan dimana metode serta fungsi tersebut berada. Untuk mengatasi permasalahan tersebut, memanfaatkan WSDL untuk mencari informasi kemudian menggunakan SOAP untuk menjelaskan fungsi public serta metode yang ditemukan.

Dalam penerapannya, web service memerlukan sumber dari semua informasi tentang SOAP message, cara membuat respons, mengumumkan service yang ada, dan sebagainya. Dengan demikian, aplikasi dapat menggunakannya untuk mencari file WSDL. Untuk memenuhi hal tersebut, diperlukan UDDI yang mampu menyediakan service untuk mencari informasi yang diperlukan. UDDI memungkinkan suatu aplikasi instansi/perusahaan untuk mengumumkan detail dari web service yang tersedia, biasanya melalui kata kunci atau deskripsi.

Semakin berkembangnya teknologi web service, maka dikembangkan sebuah sistem cerdas yang menggunakan semantic web service. Berikut ini gambar yang menunjukkan evolusi dari web [10].

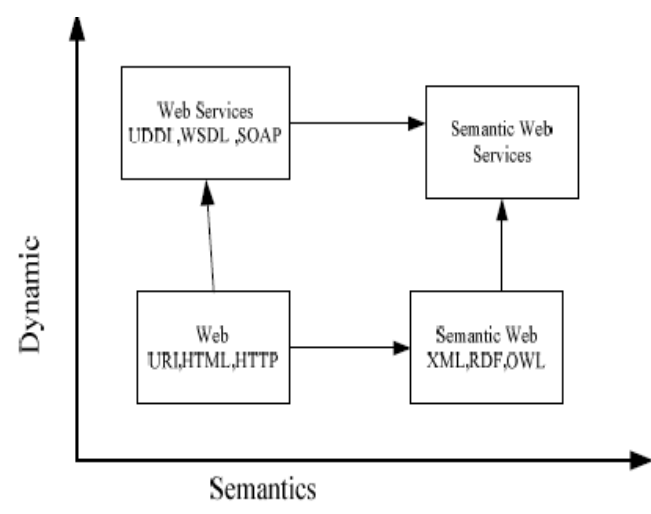

Gambar 5. Evolusi dari web

\section{Intelligent Agent dan SOA}

Intelligent agent dan multi-agent system telah mendapat banyak perhatian oleh para peneliti selama beberapa tahun terakhir. Bidang ini muncul karena mempunyai manfaat yang memungkinkan suatu aplikasi untuk memutuskan sendiri apa yang harus mereka lakukan dalam rangka untuk memenuhi tujuan yang telah didesain. Agen adalah sistem komputer yang bertindak melaksanakan tugas tersebut. Sebuah definisi secara umum dari Agen adalah komputer sistem yang terletak dalam lingkungan tertentu dan mampu melakukan tindakan sendiri dalam rangka memenuhi tujuan yang ditentukan [10].

SOA adalah suatu model komponen yang menghubungkan antar berbagai unit aplikasi fungsional, services yang digunakan, melalui antarmuka yang terdefinisi dengan baik diantara services. Antarmuka didefinisikan secara netral dan independen dari platform perangkat keras, operasi sistem, dan bahasa pemrograman di mana services ini diimplementasikan.

Web Service Composition (WSC) berbasis SOA sudah banyak diimplementasikan dan sangat signifikan untuk proyek SOA. Namun, usaha estimasi untuk suatu jenis project SOA masih terbatas karena berbagai pendekatan untuk WSC[6].

W3C membagi SOA kedalam tiga entitas yaitu Service Requester, Service Provider, dan Service Broker seperti pada gambar 6 [3]. 


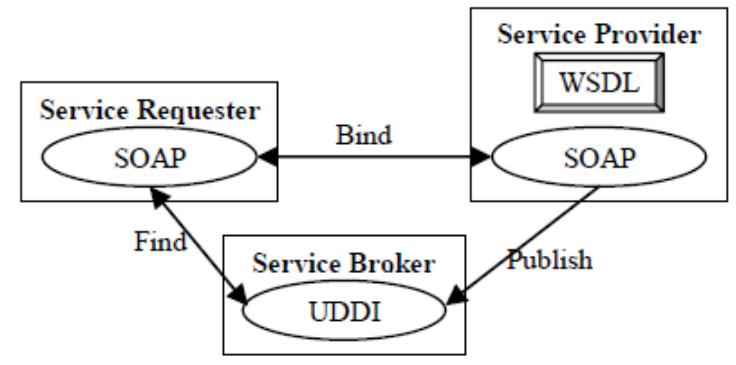

Gambar 6. Architecture dari SOA

Fitur SOA adalah enkapsulasi service, re-using service dan interaksi service. Untuk klien perusahaan, tujuan akhir dari SOA adalah pemecahan masalah dan supply service berdasarkan berbagai persyaratan [11].

Web service merupakan teknologi yang penting dalam mengimplementasikan SOA. Semua teknologi yang mengimplementasikan service interface dengan WSDL berkomunikasi dengan XML messages, termasuk SOA. Sebagaimana ditunjukkan sebelumnya, teknologi lain seperti teknologi J2EE, CORBA, dan IBM WebSphere MQ [12].

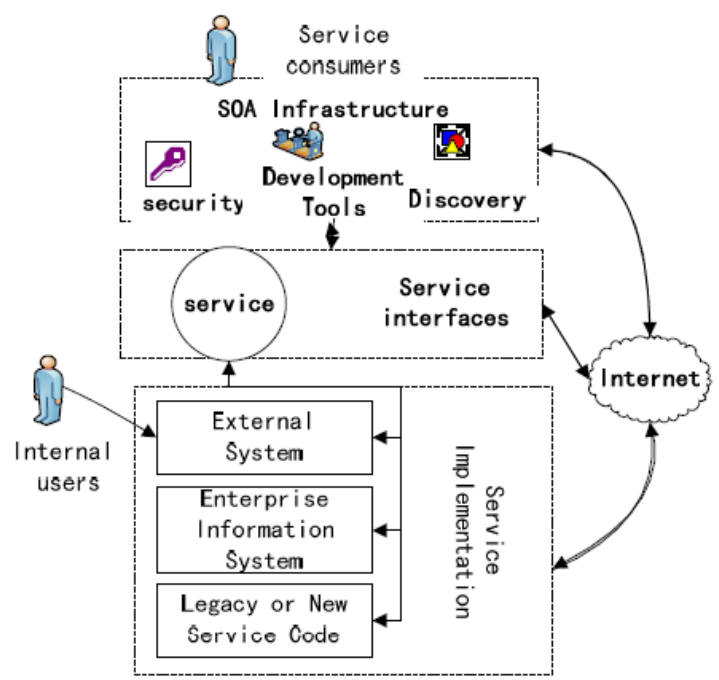

Gambar 7. Komponen dari SOA-Based system

\section{Kerangka Kerja Sistem}

Pada penelitian sebelumnya menggunakan teknologi web services untuk membangun sebuah e-learning sistem, dan menggunakan .NET untuk kode software parsial komponen di dalam sistem [8]. Penelitian berikut ini menambahkan komponen perangkat lunak menggunakan JAVA ke dalam sistem untuk mencapai yang benar dalam integrasi sistem yang sifatnya heterogen. Studi ini sistem kerangka ditunjukkan pada Gambar 8:

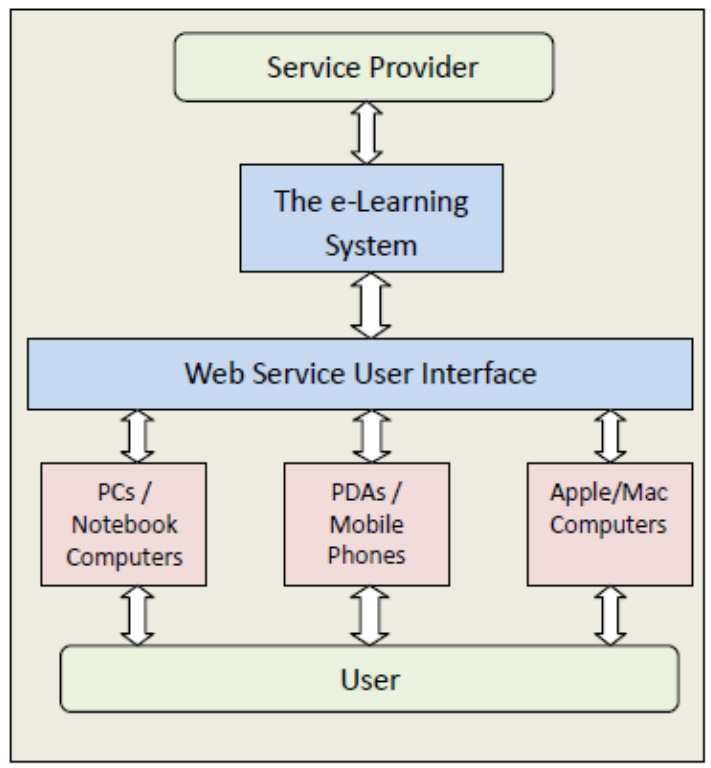

Gambar 8. Keseluruhan Kerangka Kerja Sistem Fungsi dari sistem dan content dijelaskan sebagai berikut [8]:

\section{Bulletin Board}

a. Pengumuman Informasi: Fungsi ini memberikan ringkasan dan informasi secara rinci yang berkaitan dengan pengumuman, informasi program dan skor.

b. Memasang Pengumuman: Fungsi ini memungkinkan pengguna untuk mengisi ringkasan dan isi pengumuman.

\section{Course Material}

a. Bahan Upload: Fungsi ini memungkinkan guru untuk meng-upload bahan ajar ke sistem, misalnya file power point, file word dan file PDF, untuk didownload.

b. Bahan Download: Fungsi ini memungkinkan guru atau peserta didik untuk mendownload bahan ajar dari sistem untuk menggunakan untuk mengajar atau belajar.

\section{Teaching Videos}

a. Upload Video: Fungsi ini memungkinkan guru untuk meng-upload video pelajaran untuk sistem bagi pelajar untuk download atau bermain secara online.

b. Download Video: Fungsi ini memungkinkan guru dan peserta didik untuk mendownload video pengajaran dari sistem dan menggunakannya untuk mengajar atau belajar.

c. Play Video: Fungsi ini memungkinkan peserta didik untuk langsung memutar video pengajaran secara online dengan dibutuhkan bandwidth yang cukup. 
a. Course Discussion: Fungsi ini menyediakan area untuk guru dan peserta didik untuk mendiskusikan isi pembelajaran dan pertukaran informasi.

5. Online Test

a. Proses Penilaian: Fungsi ini memberikan penilaian online saja untuk memahami seberapa baik peserta didik yang mengerti bahan ajar saja.

b. Penilaian Manajemen Informasi: fungsi ini memberikan penilaian online saja mengenai Manajemen Informasi untuk memahami bagaimana peserta didik baik memahami isi bahan ajar.

6. Tugas dan Laporan Sekolah

a. Pengumuman Tugas: Fungsi ini memungkinkan guru untuk mengumumkan informasi dan pemberitahuan terkait dengan tugas.

b. Upload Tugas: Fungsi ini memungkinkan peserta didik untuk meng-upload tugas-tugas mereka ke sistem untuk didownload pengajar dikelas.

c. Download Tugas: Fungsi ini memungkinkan guru untuk men-download tugas dari peserta didik yang sudah diupload.

Pengguna mengoperasikan fungsi sistem dengan menggunakan user interface terintegrasi yang ditunjukkan pada Gambar 8. Ketika pengguna memilih fungsi sistem, komponen sistem mulai beroperasi. Pencarian komponen sistem untuk web services dari services provider, yaitu dengan mengembalikan lokasi layanan web dalam file WSDL ke komponen sistem, dan setelah komponen sistem membaca informasi dalam file WSDL, kemudian memanggil web service menggunakan dan menampilkan hasil pengolahan pada pengguna.

\section{Kesimpulan dan Saran}

Penelitian ini menggunakan komponen web service yang dikembangkan dengan platform java dan teknologi XML yang memungkinkan untuk mengembangkan sistem e-learning dengan menggunakan web service. Dengan menggunakan teknologi dari web service, pengguna dapat menggunakan sistem e-learning menggunakan internet tanpa ada pembatasan waktu dan tempat. Selain itu bagi pengembang sistem e-learning dapat menghindari ketidakcocokan dari format data yang disebabkan karena perbedaan platform dan bahasa pemrograman yang berbeda. Penggabungan perancangan berorientasi objek dengan Software Oriented Architectures dapat digunakan untuk membangun sebuah sistem e-Learning dan mengatasi permasalahan pada sharing resource dan pencarian data.
Pada penelitian berikutnya dapat dikembangkan lagi dengan menggunakan web semantic dan Software Oriented Integration untuk membangun sistem e-learning yang lebih komplek.

\section{VII.DAFTAR PUSTAKA}

[1] Li, Jin., Song, Bo. Web Services Integration on Data Mining Based on SOA. International Symposium on Intelligence Information Processing and Trusted Computing, 2010.

[2] Ferber, Marvin., Rauber, Thomas., Hunold, Sascha. Combining Object-Oriented Design and SOA with Remote Objects over Web Services. Eighth IEEE European Conference on Web Services, 2010.

[3] Lan, Huang., Ling-ge, Sui., Chun-guang, Zhou. Research on the Sharing E-Learning Based on SOA and Semantic Web Architecture. International Conference on Computer Science and Software Engineering, 2008

[4] Luo, TaoHua., Liu, LiJun. Research on the Application Integration of Virtual PrintingEnterprise Based on SOA and Web Service. The 1st International Conference on Information Science and Engineering (ICISE2009)

[5] L'ecu', Freddy. Combining Collaborative Filtering and Semantic Content-based Approaches to Recommend Web Services. IEEE International Conference on Semantic Computing, 2010.

[6] Li, Zheng., O’Brien, Liam. A Qualitative Approach to Effort Judgment for Web Service Composition based SOA Implementations. International Conference on Advanced Information Networking and Applications, 2011.

[7] Caballé, Santi. Combining Generic Programming and Service-Oriented Architectures for the Effective and Timely Development of Complex e-Learning Systems. International Conference on Complex, Intelligent and Software Intensive Systems, 2008

[8] Chang, Chung C., Hsiao, Kou-Chan. An eLearning System for Information Management Education Based on Web Services. International Conference on Computational Aspects of Social Networks, 2010 
[9] M. Ferber, S. Hunold, and T. Rauber, "BPEL Remote Objects: Integrating BPEL Processes into Object- Oriented Applications," in Proc. of the 7th IEEE Int. Conference on Services Computing (SCC 2010), 2010,pp. 33-40

[10] Cui-Mei, Bao. Combining Intelligent Agent with the Semantic Web Services for Building An e-Commerce System. IEEE International Conference on e-Business Engineering, 2009.

[11] Honghui, Niu., Xiaojun, Ma. Research of ELearning System Based on SOA. Second International Conference on MultiMedia and Information Technology, 2010.

[12] Ying, CAO., Mier, ZHANG. Integration of Enterprise Application Based on SOA. World Congress on Software Engineering, 2009. 